\section{Ciência, técnica e cultura: relações entre risco e práticas de saúde}

\author{
Science, technique, and culture: \\ relations between risk and health practices
}

Dina Czeresnia 1

\title{
Introdução
}

1 Departamento de

Epidemiologia e Métodos Quantitativos em Saúde, Escola Nacional de Saúde Pública, Fundação Oswaldo Cruz, Rio de Janeiro, Brasil.

Correspondência Dina Czeresnia Departamento de Epidemiologia e Métodos Quantitativos em Saúde, Escola Nacional de Saúde Pública, Fundação Oswaldo Cruz.

Rua Leopoldo Bulhões 1480, 80 andar, Rio de Janeiro, $R J$ 21041-210, Brasil. dina@ensp.fiocruz.br

\begin{abstract}
This article discusses the cultural consequences of discourses and practices aimed at training subjects for a rational, informed choice in relation to risks, calculated on the basis of scientific knowledge. The epidemiological risk concept is a central element in this process, especially in the context of health practices. The article begins by briefly characterizing the epidemiological risk concept, emphasizing that as an abstract model, it reduces the complexity of the phenomena it studies. Grasping reality through this abstraction generates values and meanings. Canguilhem's reflection on the relations between science, technique, and life is further discussed from the perspective of deepening an understanding of the cultural consequences of this process, contributing to the transformation of classical concepts of individuality, autonomy, and sociability. Such vital themes as individuality, alterity, and the relationship with death are present (albeit disguised) in issues that involve the central nature of risk in the contemporary world.
\end{abstract}

Risk; Culture; Public Health Practice
A sociedade contemporânea é definida como sociedade do risco, considerado elemento central para tomada de decisão racional em face ao crescimento da incerteza na cultura moderna tardia. O indivíduo moderno é concebido como senhor de seu próprio destino, dono de sua biografia e identidade. Através da racionalidade, ele amplia o poder de controlar as situações da vida. Exerce sua autonomia mediante a capacidade de realizar, ativa e livremente, escolhas informadas que minimizam riscos 1 .

Os sujeitos utilizam reflexivamente sistemas de especialistas que gerem a vida cotidiana. A vida social é regulada pela confiança em sistemas abstratos que, baseados no conhecimento cientifico, orientam as escolhas através de cálculos de risco 2 .

O conceito de risco epidemiológico é um destes sistemas abstratos. A monitorização e a definição de estratégias de regulação de riscos no campo da saúde são tecnicamente viabilizadas pelos avanços nas técnicas de cálculo estatístico. Métodos epidemiológicos sofisticados são utilizados na estimativa da probabilidade de ocorrência de eventos de saúde e doença associados a determinadas exposições. $\mathrm{O}$ estudo dos efeitos prováveis do consumo de substâncias, de comportamentos, e de estilos de vida informam profissionais de saúde e os sujeitos em suas práticas cotidianas. As políti- 
cas e programas voltados para a proteção e recuperação da saúde podem ser considerados como ações de gestão de riscos 3 .

Identificar e reduzir riscos tornou-se um objetivo central da saúde pública. A gestão de riscos é nuclear ao discurso de promoção da saúde, que busca reorientar as estratégias de intervenção na área da saúde. Na definição explicitada na Carta de Ottawa 4, promoção da saúde é o processo de capacitação da comunidade para que ela própria possa participar e controlar ações para a melhoria da sua qualidade de vida e saúde. Este processo de capacitação, que enfatiza a autonomia dos sujeitos e grupos sociais na gestão da saúde e na luta coletiva por direitos sociais, é informado pelo conhecimento científico dos riscos à saúde.

Uma pergunta importante é que concepção de sujeito está sendo moldada através de discursos e práticas voltados à capacitação para escolha informada de riscos à saúde, calculados com base no conhecimento científico.

A técnica, baseada na ciência, produz representações, discursos, experiências, afetando o corpo e os processos psíquicos. As conseqüências e implicações culturais do conceito de risco no mundo contemporâneo não se restringem ao risco epidemiológico, mas, sem dúvida, ele é um elemento central deste processo.

Este texto busca contribuir para a reflexão deste tema. Inicialmente apresenta uma breve caracterização do conceito de risco epidemiológico, ressaltando que, como modelo abstrato, reduz a complexidade dos fenômenos que estuda. A apreensão da realidade mediante essa abstração gera valores e significados.

A reflexão de Canguilhem sobre as relações entre ciência, técnica e vida é retomada com a perspectiva de aprofundar a compreensão das conseqüências culturais produzidas, que contribuem para a transformação das concepções clássicas de individualidade, autonomia e sociabilidade. Essas mudanças aparecem como naturais, mas são uma construção: possibilitam conquistas, mas também criam mal estar $\mathrm{e}$ desafios.

Convergente com a análise de vários outros autores, Giddens 5 destaca, dentre as características da identidade moderna, a tendência de segregação da experiência - separação, na vida social diária, de experiências originárias que dizem respeito a questões e dilemas existenciais humanos. $\mathrm{O}$ contato com situações que ligam a maioria dos indivíduos a questões mais amplas de moralidade e finitude é cada vez mais raro e fugaz 5 .

Não há dúvida que temas vitais cruciais, como individualidade, alteridade, relação com a morte, estão presentes (ocultos) nas questões que envolvem a nuclearidade do risco no mundo atual. Essas questões, que são eixo das interrogações de alguns dos mais importantes pensadores da modernidade, devem ser tocadas ao se pensar criticamente o discurso atual das práticas de promoção e recuperação da saúde, baseadas no conceito de risco.

\section{O conceito de risco epidemiológico}

O conceito de risco epidemiológico surgiu no contexto do estudo de doenças transmissíveis, pois a identificação de microorganismos não foi suficiente para explicar totalmente as causas da sua ocorrência 6 . Por exemplo, nem todos os indivíduos que entram em contato com os microorganismos adoecem; os que adoecem não apresentam a mesma gravidade. Essa constatação estimulou a utilização da estatística para buscar avaliar a probabilidade da interferência de outros fatores no processo.

Porém, o desenvolvimento do conceito e das técnicas de cálculo do risco amadureceu, a partir do final da segunda guerra mundial, com a importância crescente das doenças não transmissíveis, cujas causas não eram diretamente identificáveis. Os modelos estatísticos, aplicados a teorias biológicas, passaram a ter cada vez mais desenvolvimento e aprimoramento.

A construção dos métodos de avaliação de riscos tem a experimentação como critério básico de rigor e legitimidade científica. No trabalho experimental, a lógica é controlar todos os fatores que podem interferir na experiência, criando-se condições de observar uma relação de causa e efeito. O ideal experimental é poder comparar a causa com a não causa, estando todas as outras condições sob controle. Para inferir o risco de um ou um grupo de fatores, deve-se buscar observá-lo independentemente dos demais 7 .

Construir um modelo para medir o efeito de uma causa, ou um conjunto de causas, exige um processo de “purificação”. É necessário assumir algumas premissas que viabilizam o modelo, isolando os elementos que se deseja observar. Este processo constrói uma abstração do fenômeno estudado. Na medida em que o modelo é construído, o fenômeno passa a ser apreendido mediante uma representação, que reduz sua complexidade 8 . A construção da representação é inerente à lógica do modelo, e é justamente a simplificação que viabiliza sua operacionalização.

A abordagem do risco, por mais que se tornem mais complexos os modelos de análise, 
reduz, desconsidera aspectos dos fenômenos estudados. O desenvolvimento do método impõe artifícios para poder viabilizar sua operacionalização. As reduções, inevitáveis do ponto de vista da lógica interna do método, constroem representações que tentam "substituir" a realidade.

Ocorre aí uma inversão: a medida do risco deveria ser utilizada assumindo-se critérios de adequação à realidade complexa, mas acaba por construir representações em que a própria realidade é apreendida com base na redução operada logicamente na viabilização do método. "Apagam-se" aspectos importantes dos fenômenos. O artifício operacional pode produzir artefatos que estreitam as possibilidades de compreensão e intervenção sobre a realidade.

\section{Risco e normatividade: inversão da anterioridade da vida em relação à técnica baseada no conhecimento científico}

A proeminência do modelo construído pelo conhecimento em relação ao fenômeno concreto que ele busca explicar produz valores e conseqüências culturais.

Quando discute o conceito de normatividade em O Normal e o Patológico 9, Canguilhem afirma que é, ao contrário, a experiência vital anterior e raiz de toda atividade técnica. A reflexão que neste contexto, ele faz acerca das relações entre ciência, técnica e vida situa a compreensão das implicações culturais do conceito epidemiológico de risco.

Canguilhem dedicou-se à filosofia das ciências da vida. Porém, a filosofia das ciências da vida, mesmo mediatizada pela racionalidade das ciências da vida, encerra uma filosofia da vida 10. A filosofia da vida que se extrai da filosofia das ciências da vida em Canguilhem considera a dimensão vital do ser vivo. Essa dimensão vital está ancorada na perspectiva somática, mas, ao mesmo tempo, a transcende, permitindo sintonizar a reflexão filosófica a partir da conexão entre natureza e cultura.

A atividade normativa - capacidade de julgar e qualificar fatos em relação a uma norma, ou seja, de instituir normas - é, antes de tudo, uma propriedade da vida. "A vida não é indiferente às condições em que ela é possível, a vida é polaridade e, por isso mesmo, posição inconsciente de valor" 9 (p. 96). A normatividade essencial à consciência humana está em germe na própria vida. A necessidade terapêutica é uma necessidade vital. A cultura está inscrita na natureza. "Toda técnica humana, inclusive a da vida, está inscrita na vida" 9 (p. 99). A medicina enquanto técnica que se vale da ciência humana, é o prolongamento de uma propriedade vital. Enquanto um prolongamento do vital a técnica médica é indispensável, mas relativa 9.

A técnica médica lida com a doença dividindo-a em uma multiplicidade de mecanismos funcionais alterados. Porém, a saúde e a doença são acontecimentos que dizem respeito ao organismo na sua totalidade. O organismo apresenta um conjunto de propriedades singulares - que só pertencem a ele - graças às quais ele é capaz de se preservar defendendose da destruição. Por mais ampliado que seja o poder de intervenção da técnica baseada na ciência, haverá sempre lacunas importantes entre o conhecimento de mecanismos funcionais e o conjunto de circunstâncias que interferem na saúde e na doença do homem.

Outro aspecto desta relatividade diz respeito aos limites do aferimento experimental, que fundamenta o conhecimento e intervenção técnica, em relação às atividades funcionais fora do laboratório. "A não ser que admitamos que as condições de uma experiência não têm influência sobre a qualidade de seu resultadoo que está em contradição com o cuidado para estabelecê-las - não se pode negar a dificuldade que existe em comparar as condições experimentais às condições normais - tanto no sentido estatístico quanto no sentido normativo - da vida dos animais e do homem" 9 (p. 114).

Ocorre uma tendência de desconsiderar o aspecto redutor do conhecimento e das técnicas que se produzem por meio dele. A técnica obviamente interfere na experiência vital dos homens, ela constrói representações, discursos, experiências, e historicamente interfere também nas transformações biológicas e ambientais. Este processo incorpora as conseqüências da inversão da anterioridade da experiência vital na configuração da técnica. Instituemse normas que tendem a ocultar, na vida social, dimensões fundamentais da condição humana. Estas dimensões não são passíveis de exclusão, mas tendem a ser negadas, recalcadas.

Os resultados dessa tendência contribuíram para a transformação das concepções clássicas de individualidade, autonomia, sociabilidade e suas formas de regulação. Essas mudanças aparecem como naturais, mas são uma construção que possibilitaram conquistas, mas também mal estar e desafios. Daí a pertinência de buscar esclarecer a natureza da individualidade moderna e, especificamente, como as ciências da vida interferem nesta construção. 
A questão da individualidade na história das ciências da vida: conceitos de célula, transmissão e risco

A questão da individualidade é um tema fundamental e persistente na história das ciências. Esta afirmação está presente na análise de Canguilhem 11 sobre a teoria celular. Ele ressalta como a história do conceito de célula é inseparável da história do conceito de indivíduo e que valores sociais, afetivos e culturais estão presentes no seu desenvolvimento.

No contexto da racionalidade das ciências da vida, a questão da individualidade e os problemas teóricos que ela suscita faz distinguir dois aspectos dos seres vivos que estão intrincados na sua percepção: matéria e forma ${ }^{11}$. Do ponto de vista material, o indivíduo é divisível, estudado pela biologia através de estruturas cada vez menores. Enquanto forma, o ser vivo é uma totalidade indivisível, não existe sem estar inserido em um meio que lhe seja adequado.

A biologia conceituou o ser vivo a partir da sua estrutura material, estudada com base em fenômenos físico-químicos, correspondendo a um meio que, por sua vez, foi concebido como os componentes físico-químicos que estão em contato com a parte externa do organismo, exercendo efeito sobre ele 12. Já o ser vivo, enquanto forma, não se esgota no conceito de organismo, nem o meio em seus componentes físico-químicos. Como totalidade, na sua expressão enquanto forma, o ser vivo passa a ser objeto de reflexão filosófica, pois não se reduz à biologia no sentido estrito.

A apreensão da vida com base nesses dois aspectos da percepção dos seres vivos, apesar das diferenças, preserva elos que evidenciam características constituintes e definidoras da condição de ser vivo.

Um deles é a constatação de que o ser vivo, ao mesmo tempo em que preserva sua individualidade distinguindo-se morfologicamente do todo, só sobrevive estando em relação com o meio que o circunda. A questão da alteridade é um dado da vida. A afirmação de que o ser vivo mantém sua unidade em virtude da sua abertura e apesar desta abertura 13 tem uma dimensão biológica relativa às estruturas anatômicas e trocas físico-químicas entre meio interno e meio externo. Mas tem um sentido vital que transcende em muito essa dimensão: como o homem lida culturalmente com esta simultaneidade, entre separação e abertura; entre a preservação do indivíduo e a da espécie; entre individual e coletivo.

Os conceitos científicos, para além de uma construção racional, são também uma cons- trução simbólica. Valores relativos à individualidade e à alteridade interferiram na construção da teoria celular, como apontou Canguilhem, e também na construção das teorias sobre a propagação das doenças epidêmicas 14 . Na origem destas teorias está a percepção do contágio, isto é, de que a doença epidêmica propaga-se por meio do contato com doentes ou objetos por eles tocados. Contágio é uma experiência originária que se refere ao medo do contato com o outro. O pânico vivenciado nas epidemias esteve relacionado a atitudes obscurantistas e irracionais de rejeição.

A origem da doença na Idade Média foi associada à abertura do corpo às sensações e às circunstâncias que ampliam os espaços de permeabilidade do corpo. Os mais predispostos a adoecer seriam aqueles mais abertos ao contato e aos estímulos. Essa referência às interfaces do corpo permanece presente nos deslocamentos e descontinuidades que fizeram emergir a teoria moderna de transmissão de agentes específicos 14 .

O conceito de transmissão construiu uma nova racionalidade capaz de controlar o medo difuso associado à velha noção de contágio, permitindo alcançar formas mais efetivas de intervir sobre a propagação de doenças epidêmicas. Este conceito surgiu no século XIX, no contexto da emergência da medicina moderna. Ancorado no conceito de organismo, o conceito moderno de doença encontrou correspondência na anatomia patológica. Por sua vez, a explicação sobre a propagação das doenças epidêmicas deslocou-se dos sentidos do tato contágio - e olfato - miasma -, que produziam uma apreensão vaga, para o sentido da visão, possibilitando uma definição objetiva e precisa das origens da epidemia. A partir da descrição das lesões específicas relacionadas aos sinais e sintomas clínicos de doenças, buscou-se definir os agentes e os caminhos também específicos que seriam responsáveis pelo desencadeamento do processo inflamatório 14.

O conceito de transmissão viabilizou uma teoria de estrutura científica sobre a propagação de doenças epidêmicas. Permitindo encontrar formas mais racionais e seguras de controle das doenças, está aparentemente desconectado da carga simbólica contida na percepção original do contágio. Porém, assim como as outras teorias explicativas sobre as epidemias, ele também contém uma representação simbólica das interfaces corporais, interferindo na construção moderna da idéia de alteridade. Uma perspectiva orgânica e anatômica fez emergir o conceito de transmissão. Porém, aproximando-se do corpo com base em sua anatomia e 
morfologia, a medicina da época estava, significativamente detendo-se no estudo das estruturas de interface: a pele e as membranas mucosas 14 .

A gênese do conceito transmissão é uma das evidências sugestivas de que as interfaces do corpo são elementos de interpretação central para a compreensão da doença como fenômeno que integra as dimensões biológica e simbólica.

A teoria de doença epidêmica moderna contribuiu para a construção de representações corporais que levaram a um crescente "fechamento" das suas interfaces, tornando o corpo uma estrutura primariamente defensiva. Isto pode ser exemplificado mediante as inúmeras metáforas militares que impregnam o discurso médico. Desloca-se para um referencial externo - exacerbadamente defensivo - o que seria uma propriedade interna do homem enquanto ser vivo: a capacidade de preservar sua integridade, autonomia e identidade em relação dinâmica com o que o circunda 14, o que secundariamente não exclui a necessidade da defesa.

Estes mesmos valores não só estão presentes como se acentuaram no deslocamento do conceito de transmissão de agentes microbiológicos para o conceito de risco, como vimos, hoje predominantes nas abordagens epidemiológicas e de promoção da saúde. O conceito de risco abstrai de forma ainda mais radical a relação entre homem e meio. O conceito de transmissão representa a interface do corpo como interação entre orgânico e extra-orgânico. O conceito de risco prescinde até mesmo desta relação 15 ao se constituir com base em modelos de probabilidade da relação entre exposições - causas - e eventos - doenças 14 .

Uma interpretação conseqüente a esta análise é a de que risco caracteriza uma alternativa da sociedade moderna para lidar com o medo do contato, manifesto de modo mais trágico e cruento nas imagens do contágio das pestes medievais. Um substituto cultural das formas pré-modernas de lidar com o medo do perigo no contato com o outro 16 .

De um outro ângulo, constata-se como o processo progressivo de abstrações que configuraram os conceitos de transmissão e risco fez emergir novas estratégias de intervenção que marcaram profundas transformações na prática médica. A teoria dos germes inaugurou a concepção moderna de prevenção de doenças. O conceito de risco produziu um deslocamento importante nas práticas de prevenção.

O risco não surge da presença de um perigo localizado em um indivíduo ou grupo concreto. O objetivo não é enfrentar uma situação concreta de perigo, mas evitar todas as formas prováveis de irrupção do perigo. Dissolve-se ainda mais a noção de sujeito ou de indivíduo concreto, substituindo-a por uma combinatória de "fatores de risco". O componente essencial das intervenções deixa de ser uma relação direta - face a face - entre profissional (cuidador) e cliente (cuidado). Torna-se a prevenção da freqüência de ocorrência na população de comportamentos indesejáveis que produzem risco em geral 17.

Na perspectiva foucaultiana as estratégias de prevenção de doenças são interpretadas como capazes de exercer uma função disciplinar de controle e regulação. A lógica de normatizar diretamente o comportamento de indivíduos e grupos sociais, desloca-se com o conceito de risco. Ocorre então um processo de regulação em que os sujeitos são impelidos a realizar voluntariamente escolhas saudáveis orientadas por cálculos de risco. Neste contexto, risco na sociedade de hoje é compreendido como tecnologia moral, através da qual indivíduos e grupos sociais são manejados para estar em conformidade aos objetivos do Estado neo-liberal 18. Cria-se uma esfera de liberdade para os sujeitos, para que estejam aptos a cuidarem de si mesmos, exercendo uma autonomia regulada 19 .

Características, limites e contradições da concepção de indivíduo e autonomia que predomina na cultura ocidental contemporânea e suas articulações com o risco é um tema recorrente entre pensadores da modernidade.

\section{Risco e cultura}

O controle de riscos é um componente importante do esforço progressivo de buscar proteção contra as ameaças à vida humana, um dos elementos centrais do processo civilizador. Em O Mal Estar na Civilização 20, Freud afirma que tudo o que se busca com o fim de proteção contra ameaças de sofrimento humano faz parte da civilização. Essas ameaças são provenientes de três principais fontes: o mundo externo, o próprio corpo e as relações entre os homens. Paradoxalmente, as conquistas da civilização implicam em mal estar.

Freud se refere à existência de conflitos inconciliáveis como o que tensiona os interesses do indivíduo em relação aos da coletividade. A civilização exige renúncia e conseqüente insatisfação de instintos poderosos, produzindo grande "frustração cultural" nos relacionamentos sociais entre os homens. A civilização impõe repressão à sexualidade e à agressividade. 
A mudança para a postura ereta, a desvalorização dos estímulos olfativos, a predominância dos estímulos visuais e a tendência cultural para a ordem e a limpeza afastaram o homem da sua ligação mais íntima com a natureza, cercearam a sua sexualidade, reprimiram mais fortemente seus instintos, tornando-o mais infeliz.

Elias também ressalta que, no decorrer do processo civilizador, os aspectos mais primitivos e animais da vida humana foram associados a sentimentos de repugnância e vergonha e tenderam a ser removidos da vida social pública, banidos para os bastidores 21. Em A Solidão dos Moribundos 22, o autor analisa como a morte é uma das dimensões da vida que foi progressivamente empurrada para os bastidores durante o impulso civilizador. $\mathrm{O}$ aumento progressivo da longevidade adia o confronto com a condição de finitude do homem e isso é acompanhado de uma tendência crescente de isolar e ocultar a morte. A finitude é, contudo, incontornável e a perspectiva de controle do homem é limitada. O recalcamento ou negação desse, assim como de outros aspectos da condição humana, pode ter conseqüências mais indesejáveis do que conhecê-los e vivenciá-los de forma concreta e sem retoques.

Elias lembra como na sociedade medieval a morte era mais presente, mais familiar, menos oculta, o que não significa que o contato com ela fosse mais tranqüilo. Havia menos controle dos perigos e a morte era, muitas vezes, mais dolorosa. Não há como negar que no decorrer dos séculos que nos separam dos tempos medievais ocorreram mudanças acentuadas nas condições de vida. A vida tornou-se mais longa, mais segura em relação a eventos imprevisíveis e ameaçadores e isto se reflete nas transformações importantes dos padrões de morbidade e mortalidade das sociedades ocidentais. Porém, na busca incessante de aliviar os sofrimentos, o homem moderno afastou-se do contato com experiências fundamentais à sua humanidade. A morte faz parte da vida e, contraditoriamente, a estética asséptica que tenta varrer a morte para os bastidores da vida acaba por ter um resultado macabro que fragiliza a própria vida.

Não se trata de romantizar o passado como se ele tivesse sido melhor que o presente. Mas o resgate do passado pode trazer alguns elementos que iluminam a perspectiva crítica e vislumbram a construção de novas possibilidades. Ao recuperar-se a história e imagens dos tempos medievais, por exemplo, pode-se entrar em contato com dimensões que foram negadas e interrogar a pertinência das opções culturais do ocidente.
No decorrer do processo civilizador, a sociedade ocidental recalcou experiências que na sociedade medieval eram vividas de modo mais íntegro, construindo uma forma cultural específica de lidar com situações de conflitos insolúveis, constitutivos da condição humana. A dificuldade de lidar com o paradoxo produziu, no desenvolvimento da cultura, a fragmentação da realidade em oposições, optando-se por privilegiar valores como ordem, limpeza, proteção e controle.

A constituição da individualidade moderna implicou mudanças radicais nos modos de pensar e sentir. O refinamento dos costumes vinculou-se ao desenvolvimento de lógicas e técnicas de proteção do corpo. As fronteiras corporais tenderam a tornar-se progressivamente mais demarcadas e os corpos mais defendidos 23. O paroxismo dessa tendência seria o isolamento e assepsia total expresso na imagem fragilizada do menino-bolha utilizada por Baudrillard em A Transparência do Mal, que mobiliza a interrogação: o impedimento de qualquer contato direto com outro ser, conseqüente à manutenção da vida através da desinfecção absoluta do ambiente, já não seria a própria morte 23 .

Metáforas como essa, de separação radical entre "mundo interno" e "mundo externo" correspondem ao alto grau de individualização das sociedades ocidentais desenvolvidas. As pessoas se percebem como seres individuais, sujeitos isolados. É cada vez mais marcada a idéia do indivíduo totalmente autônomo, separado e inteiramente independente.

Há uma contradição importante nesta percepção. A estruturação da auto-identidade do indivíduo moderno tem como característica central a consideração de riscos informados pelo conhecimento especializado 5 , como é o caso do risco epidemiológico. A percepção de independência e autonomia dos sujeitos contrasta com a análise realizada neste texto que evidencia, na construção do conhecimento, um processo de abstração do sujeito, de "esquecimento" de dimensões vitais à sua singularidade.

O corpo, nos mais diversificados aspectos da sua apreensão, torna-se progressivamente objeto de escolha e opções 5 . O indivíduo "autônomo" e "independente" que realiza essas escolhas afasta-se, porém, do contato com experiências fundamentais à sua integridade. Uma dessas experiências diz respeito à capacidade de relação, que não poderia estar desvinculada da autonomia. A vida, tanto do ponto de vista biológico, como filosófico, é capacidade de preservar a individualidade, estando em relação. 
A imagem do homem como um ser totalmente autônomo, separado dos demais é distorcida e produz sentimentos de solidão e isolamento, esvaziando o sentido da existência. $\mathrm{O}$ conceito de sentido não pode ser compreendido tendo como referência um ser humano isolado. O sentido é uma categoria social, algo constituído por pessoas em grupos, interconectadas e comunicando-se entre si 22.

Ao estudar as relações entre corpo e cidade na civilização ocidental, Sennet 24 detecta a produção de progressivo afastamento em relação ao outro. Ele diagnostica como os projetos arquitetônicos modernos produzem privação sensorial, passividade e cerceamento tátil. Há no ambiente urbano uma perda cada vez maior da conexão entre corpo e espaço. O movimento e a velocidade acelerada nas cidades ajuda a dessensibilizar o corpo, tornando-o mais indiferente às dores alheias. Afirma que nosso entendimento a respeito do corpo precisa mudar, para que as pessoas passem a se importar mais umas com as outras. O individualismo moderno tem como objetivo a auto-suficiência, isto é a perspectiva de seres completos. Porém é a consciência da incompletude, o reconhecimento da nossa própria inaptidão que possibilita a compaixão cívica e a solidariedade.

A lógica da defesa acima de tudo, que impera em uma sociedade que busca incessantemente controlar riscos, acaba por transformarse no mais grave perigo, pois estes não desaparecem simplesmente porque procuramos evitá-los 24. As imagens idealizadas de plenitude entram em contradição com a necessidade de confrontarmos a nossa fragilidade, encontrando formas mais elaboradas de lidar com contradições e mesmo paradoxos inerentes à condição humana.

Todos esses autores estão se referindo à forma como se configurou a individualidade em relação ao mundo externo na civilização ocidental. Esta questão está inicialmente posta no núcleo da discussão de Freud em O Mal Estar na Civilização ${ }^{20}$. Uma interrogação que emerge a partir dessas leituras é se haveriam outros modos possíveis de conformação de representações de corpo, indivíduo e de suas fronteiras com o mundo externo, que, por sua vez, configurariam outras formas culturais de lidar com a tensão entre individual e coletivo na sociedade ocidental.

Como vimos, os conceitos de célula, transmissão, risco contribuíram na construção destas representações. Estes conceitos foram elementos de desenvolvimento técnico que produziram efeitos significativos nas mudanças de perfil de morbidade e mortalidade das popula- ções. Porém, o aumento da longevidade ocorreu acompanhado de "efeitos colaterais", analisados acima.

No decorrer do século XX, houve uma extraordinária e veloz ampliação da capacidade técnica da medicina. Aumentou muito a capacidade de serem tratados os mecanismos das doenças, isso em si teve poder para diminuir sofrimentos, mas ocorreu também um afastamento cada vez maior do sofrimento concreto dos homens. A afirmação de que "o cuidado com as pessoas às vezes fica muito defasado em relação ao cuidado com seus órgãos” 22 (p. 103), expressa muito bem essa contradição.

Este problema está relacionado à tensão entre técnica médica e necessidades vitais, $\mathrm{cu}$ ja raiz está na duplicidade na percepção dos seres vivos - matéria e forma -, detectada por Canguilhem. A técnica médica se constrói privilegiadamente com base na percepção do ser vivo enquanto matéria, já o vital manifesta-se no ser vivo enquanto forma. Uma diz respeito à noção de vida das ciências da vida, do estudo de mecanismos físico-químicos, fundamento cognitivo das intervenções da técnica médica. A outra à vida que se manifesta como acontecimento, em sua totalidade.

Encontrar modos conscientes e criativos de considerar a complexidade desta duplicidade é um desafio para os que buscam alternativas mais consistentes de transformação das práticas de saúde 25 .

Esta idéia encontra convergência com a perspectiva utópica que Santos 26 formula ao reivindicar que o uso da técnica possa ser feito permitindo ao homem crescer em sua humanidade. Ele afirma que hoje são dadas condições materiais para uma grande mutação da humanidade, mas que a mutação tecnológica deveria ser acompanhada igualmente de uma mutação filosófica. "Muito falamos hoje nos progressos e nas promessas da engenharia genética, que conduziriam a uma mutação do homem biológico, algo que ainda é domínio da história da ciência e da técnica. Pouco no entanto, se fala das condições, também hoje presentes, que podem assegurar uma mutação filosófica do homem, capaz de atribuir um novo sentido à existência de cada pessoa, e também do planeta" 26 (p. 174).

Elias 22 (p. 95) expressa um pensamento semelhante ao afirmar: "no presente, o conhecimento médico é em geral tomado como conhecimento biológico. Mas é possível imaginar que, no futuro, o conhecimento da pessoa humana, das relações das pessoas entre si, de seus laços mútuos e das pressões e limitações que exercem entre si faça parte do conhecimento médico". 
Uma “mutação filosófica” certamente exigiria o esforço de encontrar novas formas de conviver com o conflito entre individualidade e alteridade, que pressuporia a valorização de ambos. Isto não seria possível sem entrar em contato e conseguir reelaborar experiências originárias que mobilizaram a opção da civilização para o pólo da ordem, da defesa e do controle. Uma abertura ao risco 27 , além do seu controle, é também condição básica para se conquistar e promover saúde.

\section{Resumo}

Este artigo tem como objetivo discutir conseqüências culturais dos discursos e práticas voltados à capacitação dos sujeitos para a escolha racional e informada de riscos, calculados com base no conhecimento científico. O conceito de risco epidemiológico é um dos elementos centrais deste processo, especialmente no contexto das práticas de saúde. Inicialmente é apresentada uma breve caracterização do conceito de risco epidemiológico, ressaltando que, como modelo abstrato, reduz a complexidade dos fenômenos que estuda. A apreensão da realidade mediante essa abstração gera valores e significados. A reflexão de Canguilhem sobre as relações entre ciência, técnica e vida é retomada com a perspectiva de aprofundar a compreensão das conseqüências culturais produzidas, que contribuem para a transformação das concepções clássicas de individualidade, autonomia e sociabilidade. Temas vitais cruciais, como individualidade, alteridade, relação com a morte, estão presentes (ocultos) nas questões que envolvem a nuclearidade do risco no mundo atual.

Risco; Cultura; Prática de Saúde Pública

\section{Agradecimentos}

Agradeço a leitura e valiosas sugestões de Sandra Caponi. 


\section{Referências}

1. Beck U. A reinvenção da política: rumo a uma teoria da modernização reflexiva. In: Giddens A, Beck U, Lash S, organizadores. Modernização reflexiva. São Paulo: Editora Unesp; 1997. p. 11-71.

2. Giddens A. A vida em uma sociedade pós-tradicional. In: Giddens A, Beck U, Lash S, organizadores. Modernização reflexiva. São Paulo: Editora Unesp; 1997. p. 73-133.

3. Spink MJP. Tópicos do discurso sobre risco: riscoaventura como metáfora na modernidade tardia. Cad Saúde Pública 2001; 17:1277-311.

4. Organização Mundial da Saúde. Carta de Ottawa. In: Ministério da Saúde/Fundação Oswaldo Cruz. Promoção da saúde: cartas de Ottawa, Adelaide, Sundsvall e Santa Fé de Bogotá. Brasília: Ministério da Saúde; 1986. p. 11-8.

5. Giddens A. Modernidade e identidade. Rio de Janeiro: Jorge Zahar Editor; 2002.

6. Susser M. Causal thinking in the health sciences. New York: Oxford University Press; 1973.

7. Czeresnia D, Albuquerque MFM. Modelos de inferência causal: análise crítica da utilização da estatística na epidemiologia. Rev Saúde Pública 1995; 29:415-23.

8. Stengers I. Quem tem medo da ciência? Ciência e poderes. São Paulo: Editora Siciliano; 1990.

9. Canguilhem G. O normal e o patológico. Rio de Janeiro: Forense-Universitária; 1978.

10. Machado R. Ciência e saber. Rio de Janeiro: Editora Graal; 1988.

11. Canguilhem G. El conocimiento de la vida. Barcelona: Editorial Anagrama; 1976.

12. Jacob F. A lógica da vida: uma história da hereditariedade. Rio de Janeiro: Editora Graal; 1983.

13. Canguilhem G. Ideologia e racionalidade nas ciências da vida. Lisboa: Edições 70; s.d.

14. Czeresnia D. Do contágio à transmissão: ciência e cultura na gênese do conhecimento epidemiológico. Rio de Janeiro: Editora Fiocruz; 1997.
15. Ayres JRMC. Sobre o risco: para compreender a epidemiologia. São Paulo: Editora Hucitec/ABRASCO; 1997.

16. Douglas M. Risk and blame: essays in cultural theory. London/New York: Routledge; 1992.

17. Castel R. From dangerousness to risk. In: Burchell G, Gordon C, Miller P, editors. The Foucault effect: studies in governamentality. Chicago: University of Chicago Press; 1991.p. 281-98.

18. Lupton D. Risk: key ideas. London: Routledge; 1999.

19. Petersen A. Risk, governance and the new public health. In: Petersen A, Bunton R, editors. Foucault, health and medicine. London/New York: Routledge; 1996. p. 189-206.

20. Freud S. O mal estar na civilização. Rio de Janeiro: Imago; 1990.

21. Elias N. O processo civilizador 1. Rio de Janeiro: Jorge Zahar Editor; 1994

22. Elias N. A solidão dos moribundos seguido de envelhecer e morrer. Rio de Janeiro: Jorge Zahar Editor; 2001.

23. Rodrigues JC. O corpo na história. Rio de Janeiro: Editora Fiocruz; 1999.

24. Sennet R. Carne e pedra: o corpo e a cidade na civilização ocidental. Rio de Janeiro: Editora Record; 1997.

25. Czeresnia D. The concept of health and the diference between promotion and prevention. Cad Saúde Pública 1999; 15:701-10.

26. Santos M. Por uma outra globalização: do pensamento único à consciência universal. Rio de Janeiro: Editora Record; 2000.

27. Caponi S. A saúde como abertura ao risco. In: Czeresnia D, Freitas CM, organizadores. Promoção da saúde: conceitos, reflexões, tendências. Rio de Janeiro: Editora Fiocruz; 2003. p. 55-77.

Recebido em 24/Fev/2003

Versão final reapresentada em 14/Abr/2003

Aprovado em 20/Set/2003 